\title{
Impact of Urban Transit System on Housing Rents Evidences from India
}

\author{
Rahul TIWARI, Maulana Azad National Institute of Technology (MANIT), Bhopal, India \\ Jayant SINGH, Maulana Azad National Institute of Technology (MANIT), Bhopal, India \\ Navneet KUMAR, Maulana Azad National Institute of Technology (MANIT), Bhopal, India
}

\begin{abstract}
Public Transport is considered a sustainable mode of mobility, in light of lesser per capita carbon footprint; studies suggest the majority public transit users are from lower or middle income groups (Kyungsoon Wang, 2017). In order to strengthen the public transit ridership, the concept of Transit Oriented Development (TOD), featuring high density affordable residential neighbourhoods near the transit station, has been coined and implemented world over. It has been observed during literature review that proximity to transit has a positive impact on land value, while there is a mixed literature on the association between transit proximity and real estate values, there is scant literature relating transit proximity to real estate rents.
\end{abstract}

As India is striving to achieve affordable housing for all by year 2025 and for achieving this goal providing self-owned housing is the biggest challenge. Therefore, recently India adopted Rental Housing Policy (RHP) which envisages promoting affordable rental housing as an alternative choice of housing. Studies found that citizens who lived in affordable rental housing belong to economically weaker sections whose primary mode of transport is public transit. Therefore, it is quite important to validate the impact of transit service on housing rents. This research paper thus analyses the relationship between housing rents \& transit proximity. Transit network of Bhopal city was mapped along with housing rents of different areas as derived from the property listing websites. Using data regarding location and pricing extracted from property rental websites and the transit station coordinates, the association between transit corridor proximity and rents with respect to distance from the transit corridor centrelines is estimated. A hedonic model for estimating this effect of transit systems on housing rents was used for the city of Bhopal, India. The model is used to estimate the external benefits concerning property rental values which may be attributed to the public transport service at the present time. Impact of public transit systems on housing rents was found significant, with strong positive associations between housing rents and transit station proximity. Implications are offered for land use planning along public transport in order to promote affordable housing near transit stations.

\section{Keywords}

Urban; Transit; Impact; Housing; Rent; India 


\section{Introduction}

India is on the verge of urban transformation. In 2015, the country's urban population surpassed 420 million people, accounting for $33 \%$ of the overall population. By 2050, it is predicted to be double folded to 800 million people, with one in every two Indians living in towns and cities. As India's urban population grows, so does the country's housing need, particularly among the poor who live in slums. More than $22 \%$ of urban households lived in slums in the 2543 cities in which there were slums (Census, 2011). Economic growth, strict planning and development laws that result in inefficient land use, and speculative land and real estate investment have led to an upward push in the price of land and house in cities, as well as a decrease in housing affordability. Housing shortages affect mostly the EWS and LIG, and the younger group of urban migrants changing cities in search of better prospects, affordable houses. Everyone deserves a safe place to live in. Today, however, most cities across the world have significant issues in providing secure and suitable housing for their citizens, particularly in rapidly growing areas with limited low-cost housing options. Even people with consistent incomes struggle to find an affordable home to buy or rent.

Transit system of any city is an important element for the city's growth. People rely on transit to travel daily. A city's movement is maintained via on-time trains and buses, traffic-free highways, and cycling and pedestrian routes. As cities grow, they often become denser, more congested, and more complex. Good transportation, in turn, brings people closer together, saving time and money while also making it easier for businesses to trade, all of which contributes to the economy's growth. A strong urban transport system is crucial for city efficiency, given the need for mobility in cities (Shivakumar Nayka, 2019). To maximise the benefits of improved transit accessibility, transit-oriented development (TOD) promotes the utilisation of built-environment variables such as mixed-use, density, and walkability. There are various studies to support the transit impact on housing prices. The effects of BRT on property values varies depending on the level of property prices (Mathur, 2020).The accessibility and proximity effects of BRT across the whole price spectrum are studied in this research so that it can answer some questions such as "does housing prices depend upon the accessible distance? Does accessibility to nearest public transit have different effects on rental charges at different locations?

To answer the above-mentioned issues, we applied a sampling approach and a hedonic model to mimic transit accessibility and proximity impact in rental homes in Bhopal, India, based on 55 observations. This study addresses the gap by evaluating the impact of transit-oriented conditions on home rental values near transportation node. A method for assessing the effect of public transit on home rental values is proposed in this paper. This approach is capable of properly depicting Bhopal's present status of urban transportation and housing linkage. A hedonic model was employed to evaluate the effect of transportation networks on housing rentals when it came to model selection. The model is designed to determine the external advantages of public transportation in terms of existing property rental prices.

\section{Literature Review}

Public transit services provide riders with station-to-station services. People who reside near the public transit stations may usually take use of public transit so ridership of public transit increases at the proximity of transit stations. Housing renters are prepared to pay more for a home with strong accessibility to the transit stations. Many researchers have established that there is a favourable relationship between transit accessibility and home prices. On the other hand, it causes many serious concerns for residents near transit stations like noise/air pollution, unattractive environment. More transport choices could be added if transit facilities are introduced and cut the time it takes to get to the CBD (Central Business District). According to land rent theory, the most preferable location with a high 
level of accessibility is a central business district; however, as we go away from the zero distance, rent decreases significantly since available land expands exponentially as we move away from the most accessible area (Pászto V., 2020). According to certain theories, transit accessibility impacts rentals in the housing sector because the more accessible and area is via transport, the more desirable the place is and the higher the rent. The low housing economy is based on affordability and, more crucially, proximity to public transportation inside the city (Shrish B Patel, 2018). By connecting Greenfield sites situated in the peri-urban region to feeder services via high-frequency BRTS, affordable housing may be supplied for all income levels in urban areas, particularly those who reside in Greenfield sites situated in the peri-urban region. High-income families with one or more automobiles are the most vulnerable to highway network expansion, whereas low-income families without access to vehicles are disproportionately impacted by the construction of the BRT line (Ali Shirzadi Babakan, 2015). Construction of affordable housing developments in a suitable community location or an environment that promotes non-automobile travel preferences is one answer for low-income inhabitants' access to both work and non-work activities. Lowincome households are more likely to live in neighbourhoods that are more location-efficient, with smaller homes, better transportation access, and lower rates of automobile ownership (Gregory L. Newmark Ph.D, 2015). Building inexpensive multifamily dwellings and tenements in preferably sufficient areas that are more accessible as it is getting tremendously expensive, according to a recent research in California. As a result, some regulatory relief is being granted to developers in exchange for experimenting with towns that have less stringent parking regulations. Creating housing dwelling units for low-income tenants who are unlikely to possess vehicles by building multifamily homes and tenements with relatively minimal onsite parking seems equitable.

Cities are constructing public transportation through equitable Transit-Oriented Development policies to alleviate the negative consequences of rising property values induced by immigration to urban regions. Demand for fairly priced housing is growing in almost every city in the country, but it is growing considerably faster near public transportation. Cities around the country have adopted and implemented regulations to help people buy, develop, and maintain affordable homes near public transit. TOD Funds are a source of funding for land acquisition, the construction or maintenance of affordable housing or community services near public transit (Emily Thaden, n.d.). On a worldwide basis, TOD is gaining popularity as a recognised strategy for attaining Smart Growth and Sustainable Development. TOD improves transit station accessibility by constructing a pedestrian and Non-Motorized Transport (NMT)friendly structure that benefits a large number of people, hence increasing ridership and enhancing the facility's financial and financial feasibility (Renne, 2009).

To evaluate the effect of transportation networks on housing rentals, hedonic model is selected for the research. According to (David R.Bowes, 2001), proximity near transit stations is deemed undesirable in Atlanta due to noise and perceived safety concerns. The value of properties within a quarter-mile buffer of transportation stations is 19 percent lower than comparable properties three miles away. Homebuyers are prepared to pay more for homes in TODs, according to previously developed hedonic models (Belden, 2003). Some researches imply that higher-priced residential units require proximity to transit stations, improved pedestrian facilities, and urban planning (Keith Bartholomew, 2011).

\section{Research Method and Data Collection}

The target sampling approach has been used in the study to establish the link between affordable housing and public transportation. Samples were obtained from various locations of Bhopal city along the city's transportation network through the property listing websites. 


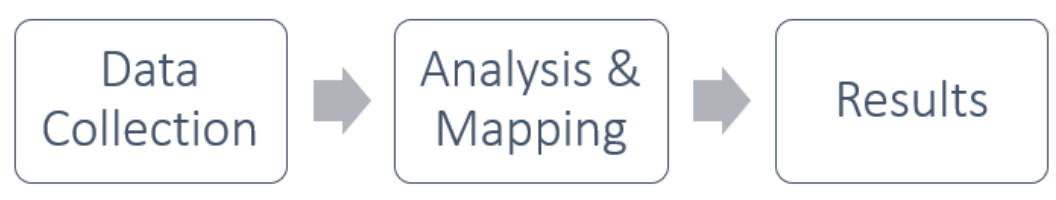

There were 55 rental housing properties sampled, which were then plotted on the Bhopal city transport route map, based on their distance from the nearest public transportation, a link is formed between the affordability of rental housing and transit. This was done on the basis of documenting the rental price indicated on the website along with other details like floor area, location, amenities etc. From the nearest transportation stop, we examined the rental property's accessibility. GIS mapping is performed in this analysis, and selected properties are displayed. The Figure 1 depicts the locations of bus stops and rental residences in the city used in this study.

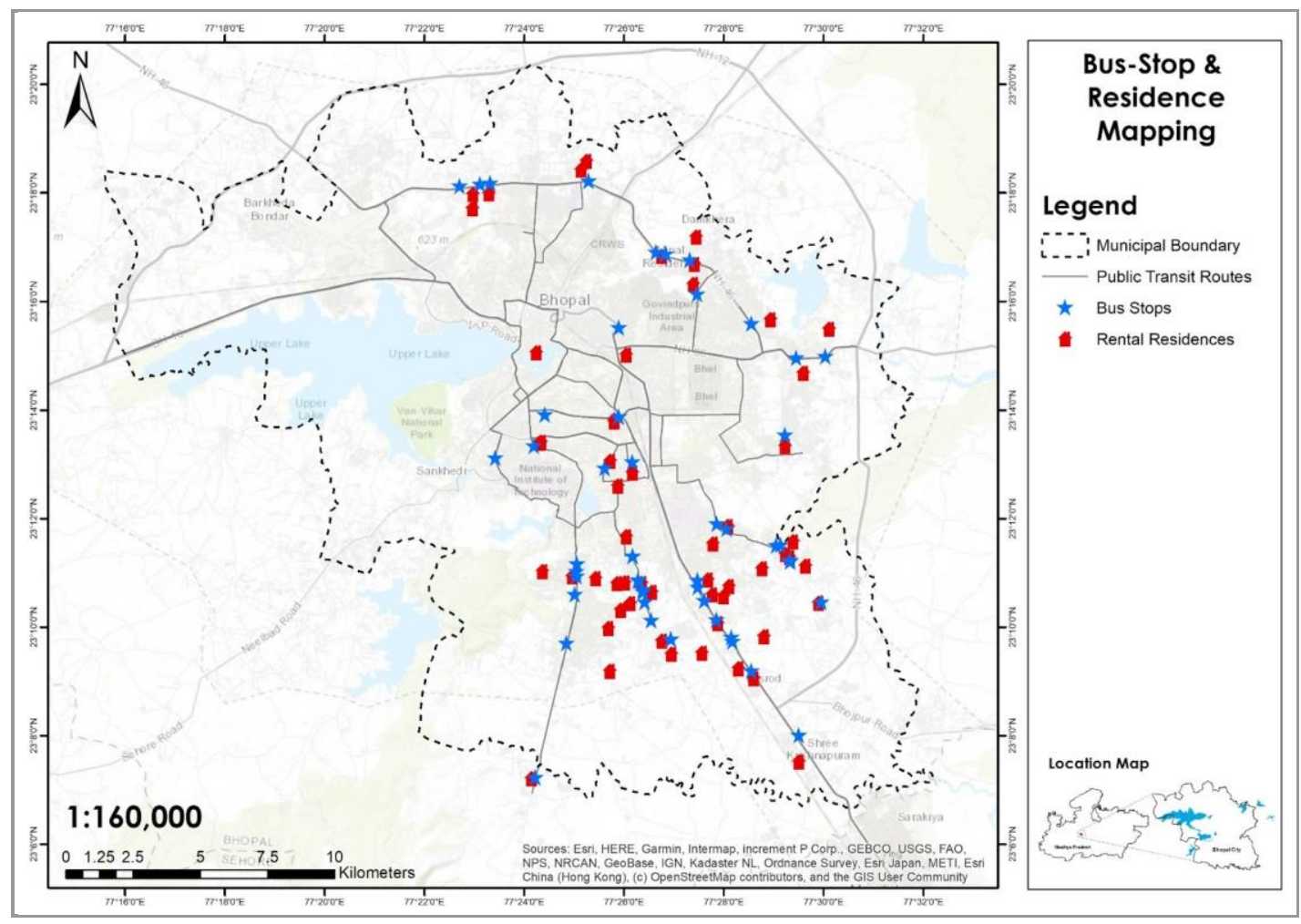

Figure 1. Bus-Stop \& Residence Mapping, Bhopal. Source: Authors

\section{Data Analysis}

Using the variables $\mathrm{x}$ and $\mathrm{y}$ to calculate the correlation coefficient, where $\mathrm{x}$ is the monthly rent and $\mathrm{y}$ is the distance from public transportation stops.

$$
r=\frac{\sum x y-N \overline{x y}}{\sqrt{\left(\sum x^{2}-N x^{2}\right)\left(\sum y^{2}-N y^{2}\right)}}
$$

Where:

$$
\begin{array}{ll}
\mathrm{N} & =\text { Number of pairs of scores } \\
\Sigma \mathrm{xy} & =\text { sum of the product of paired scores }
\end{array}
$$




$$
\begin{array}{ll}
\Sigma \mathrm{x}^{2} & =\text { sum of squared } \mathrm{x} \text { scores } \\
\Sigma \mathrm{y}^{2} & =\text { sum of squared } \mathrm{y} \text { scores } \\
\bar{x} & =\text { average of } \mathrm{x} \text { scores } \\
\bar{y} & =\text { average of } \mathrm{y} \text { scores }
\end{array}
$$

The tabulated data was to be checked for correlation, and since the data was discrete and continuous, hence Pearson's correlation coefficient was chosen to be applied on the data. Pearson correlation coefficient method was attempted on the data hence received and results of the statistical analysis were obtained, as shown in Table. It was found that the rent and distance values are negatively correlated, the correlation coefficient was found to be negative at $(r=-0.2115)$ and is significant with $p$ value less than $0.05(0.008)$, indicating that the two variables are inversely proportional i.e., as the distance from public transportation increases, the rent value drops, and vice versa. However, because public transportation users are not wealthy, they cannot afford to reside near public transit services. These results also justify the fact that the rental value of houses near public transport is higher as compared to those which are far from it. As the basic concept of transit oriented development is to create affordable housing near the transit stations so that the lower and middle income group citizens, who are the real users of public transport, can reside in the transit influence zone. The analysis found that the principles of TOD are being defeated in this case.

Table 1: Pearson correlation coefficient between rent and ditance from public transit.

\begin{tabular}{|l|c|c|}
\hline Variables & Disatnce from Public Transit & Level of Significance \\
\hline Rent & -0.212 & 0.008 \\
\hline
\end{tabular}

Source: Authors

In Figure 2 study of rent and distance values is done with a two-period moving average. The red line presented is generated by averaging the specific data values which smoothes out variations in data to show a trend more clearly.

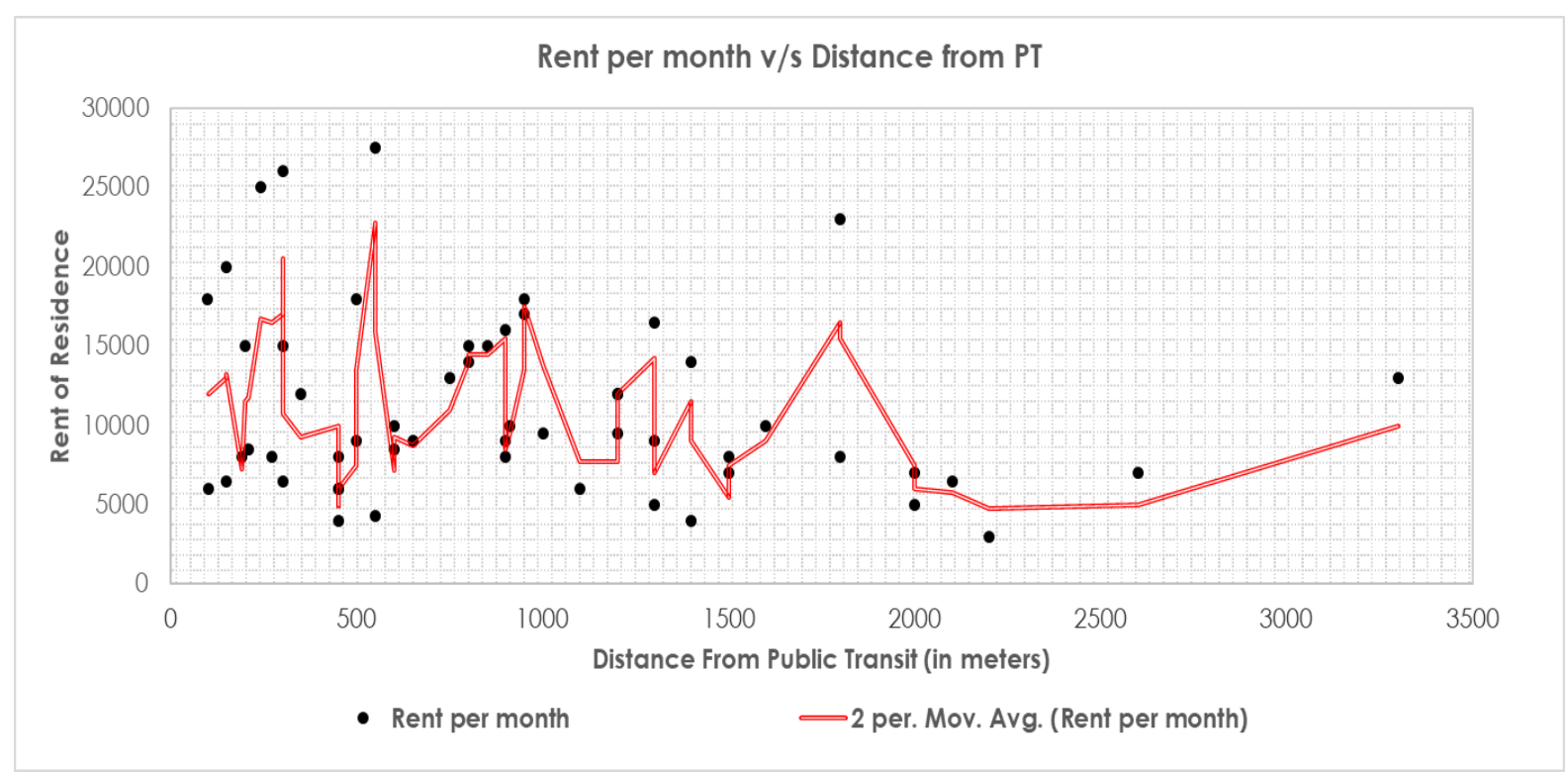

Figure 2. Two period moving average analysis between Rent and Distance. Source: Authors 
In Figure 2, a moving average is added on a scatter chart which is based on the $x$-values plotted in the chart. Therefore, the desired results are calculated by sorting the data present in $\mathrm{x}$-values before adding the trendline.

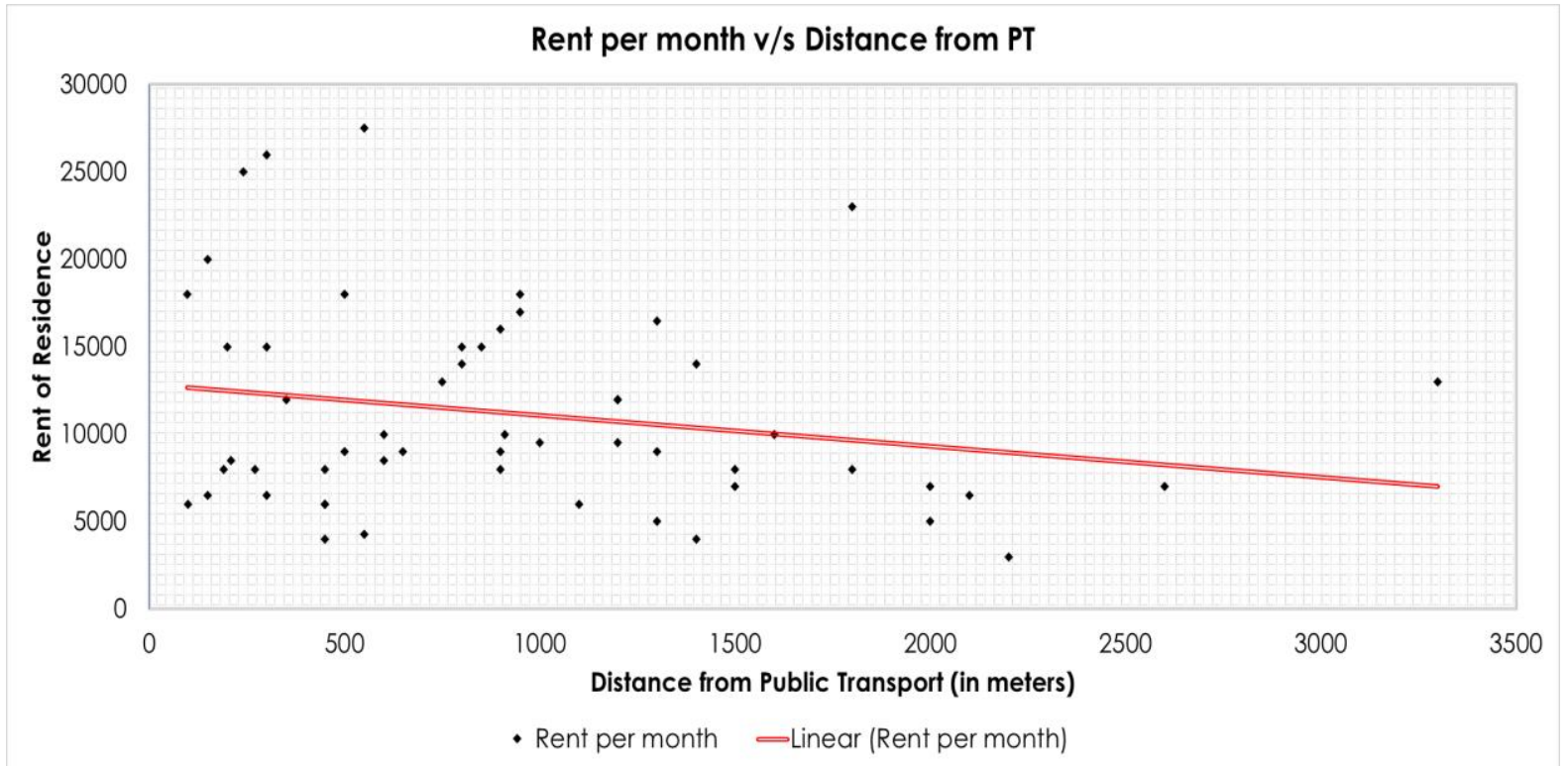

Figure 3. Linear variation between Rent and Distance. Source: Authors

When the rent per month values is compared to the distance from public transit points (bus stops) in the graph above, the trendline clearly shows that as the distance from public transit increases, the rent per month values decrease, and if the distance values decrease the rent per month values tend to increase as shown in Figure 3. While mapping both the parameters, rent and distance, the first step begins with the collection of rent and public transit data points, followed by the creation of a consecutive buffer along the public transit data points ranging from 500-3500 meters. Further, the rent of residence is combined with the buffer distances which tells us the impact of distance from public transit on rent of residences nearby, proving the point that rents near public transit are higher and away from public transit are lower, making unaffordable for the commuters of public transport and also impacting the user accessibility as well as the capability of the public transportation system as shown in Figure 4.

\section{Findings and Conclusions}

In this study, 55 rental houses were selected and identified based upon target sampling in the urban areas of Bhopal. The rental value and the disatence from the nearest transit station were compiled from a number of different property listing websites. Their rental expenses and built-up space are used to calculate rent per unit area (sq. $\mathrm{ft}$ ). The nearest public transportation station, as well as the distance between the transit station and selected dwellings, were noted. Study found that rental rates increase significantly as we approach closer to the public transit station, and that rental costs decrease significantly as we approach further away from the public transit station. It depicts that it is unaffordable for residents to live near the public transport station, as the majority of those who utilise public transportation are not comfortable financially. Therefore this study address that accessibility and connectivity has a greater impact on residential rental prices. This study fills the gap by examining the influence of transit-oriented conditions on house prices near public transportation. A method for evaluating the influence of public transportation on property values is presented in this study. 


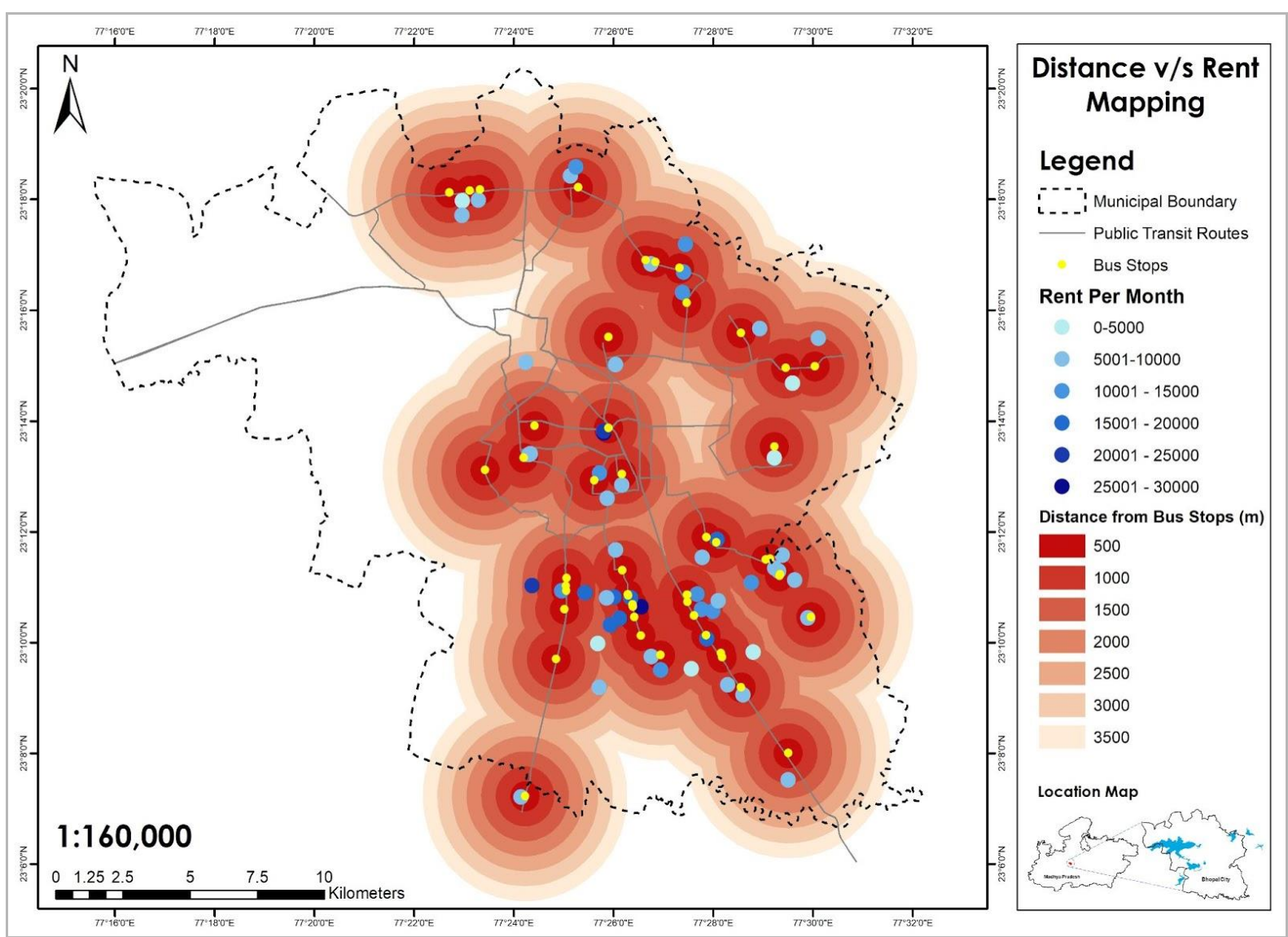

Figure 4. Residential Rents v/s Distance from Public Transit. Source: Author

The chosen methodology is capable of accurately representing Bhopal's current state of urban transportation. When it comes to model selection, a hedonic model was used to analyze the influence of transit networks on home rents. The model is intended to calculate the external benefits of public transportation in terms of current property rental rates.

The findings of the study make it inevitable for the city planners and administrators, to look into the aspects of affordability and housing rents, when planning for an inclusive public transport. As it has been observed that public transport leads to gentrification of an area, where the lower and middle income group citizens may not be able to afford living in that area on account of high rental price. A need for policy on regulating the value of the housing rental in the transit influence zone may be considered in order to make the economically weaker sections of society to live near transit and use it. This will also increase the ridership of public transport thereby making the cities transport system more sustainable, economically as well as environmentally. 


\section{References}

Ali Shirzadi Babakan, M. T., 2015. Impacts of transport development on residence choice of renter households: An agent-based evaluation. Elsevier.

Belden, N. B. J. R. a. K. S., 2003. Attitudes toward Walking and Creating Better Walking Communities, Washington, DC: Belden Russobello \& Stewart Research and Communications Institutional Report.

Census, 2011. Housing Census Data - 2011. [Online]

Available at: www.censusindia.gov.in

Cohen, J. P. C. C. C., 2008. Spatial Hedonic Models of Airport Noise, Proximity, and Housing Prices. Journal of Regional Science.

David R.Bowes, K. R. I., 2001. Identifying the Impacts of Rail Transit Stations on Residential Property Values. Journal of Urban Economics, Elsevier.

Emily Thaden, M. P., n.d. Creating \& Preserving Reasonably-Priced Housing near Public Transportation, s.I.: Lincoln Institute of Land Policy.

Gregory L. Newmark Ph.D, P. M. H. P., 2015. Income, Location Efficiency, and VMT: Affordable Housing as a Climate Strategy. Housing California.

Keith Bartholomew, R. E., 2011. Hedonic Price Effects of Pedestrian- and Transit-Oriented Development. Sage Journals.

Kyungsoon Wang, M. W., 2017. The relationship between transit rich neighborhoods and transit ridership: Evidence from the decentralization of poverty. Applied Geography, Elsevier.

Mathur, S., 2020. Impact of transit stations on house prices across entire price spectrum: A quantile regression approach. Land Use Policy, Science Direct.

Pászto V., C. J. P. T. a. J. B., 2020. Economic Geography. Springer.

Renne, J. L., 2009. Transit oriented development: making it happen. s.I.:Routledge.

Shivakumar Nayka, K. S. S., 2019. Urban Commuters in Indian States and Cities: Modes of Treansport and Distances. SAGE Publications, p. 39.

Shrish B Patel, J. S. O. K., 2018. Affordable housing needs affordable transit. 